\title{
Pruritic cutaneous lesions on the chest
}

We present the case of an 82 years old woman with history of Diabetes mellitus type 2 and arterial hypertension, chronically medicated with insulin glargine 20 units/day and amlodipine/ valsartan 5/160 mg per day. The patient was admitted to the emergency department due to dyspnea and chest pain with 1 day evolution, reporting also a 3-months history of asthenia and pruritic cutaneous lesions on the chest. On admission the patient was pale, polypneic and tachycardic with erythematous cutaneous lesions localized on the anterior and posterior thoracic region. Blood examination showed microcytic anaemia (Haemoglobin 9.1 g/dl) and elevation of D-dimer (D-dimer 4599 $\mathrm{ng} / \mathrm{mll}$. Arterial blood gas revealed hypoxemia and hypocapnia. Chest angiotomography exhibited pulmonary thromboembolism and enoxaparin was instituted. Thoraco-abdomino-pelvic computed tomography (CT) exhibited a gastric neoplasm with invasion of hepatic left lobe and local adenomegalies. The gastric biopsy confirmed the diagnosis of gastric adenocarcinoma. Skin lesions biopsy revealed histological findings compatible with bullous pemphigoid (BP) and treatment with prednisolone 40 $\mathrm{mg} /$ day was started. In cancer multidisciplinary consultation it was decided to initiate palliative chemotherapy. The patient died 6 months after the diagnosis.

$\mathrm{BP}$ is the most common autoimmune blistering disease, occurs mostly in elderly patients and it is characterized by autoantibodies deposition at the epithelial basement membrane zone..$^{1-4}$ Classically presents with an intensely pruritic eruption with tense subepithelial blisters filled with a serous or haemorrhagic content. ${ }^{1-4}$ Bullous phase may be preceded by a prodromal phase lasting weeks to months and characterized by pruritic eczematous, papular or urticarial-like lesions. ${ }^{1-4}$ In the presented case, the patient was in the nonbullous phase which made the diagnosis difficult. ${ }^{4}$ The association between malignant neoplasms and BP has been emphasized, but it is unclear whether coexisting malignancy and BP patients are pathogenically connected or whether the association is merely linked to aging. ${ }^{4,5}$ Corticosteroids are the first line of treatment, but other immunomodulatory therapies are often necessary. ${ }^{2}$ This case alerts to a less obvious presentation of the PB and its association with a neoplasm.

\section{References}

1. Baum S, Sakka n, Artsi O, Trau H, Barzilai A. Diagnosis and classification of autoimmune blistering diseases. Autoimmun Rev 2014; 13:482-489.

2. Kasperkiewicz M, Zillikens D, Schmidt E. Pemphigoid diseases: Pathogenesis, diagnosis, and treatment. Autoimmunity 2012; 45: 55-70.

3. Kershenovich R, Hodak E, Mimouni D. Diagnosis and classification of pemphigus and bullous pemphigoid. Autoimmun Rev 2014; 13:477-481.

4. Schmidt E, Torre R, Borradori L. Clinical Features and Pratical Diagnosis of Bullous Pemphigoid. Dermatol Clinic 2011; 29: 427-438.

5. Ruocco E, Wolf R, Caccavale S, Brancaccio G, Ruocco V, Lo Schiavo A. Bullous pemphigoid: associations and management guidelines: facts and controversies. Clin Dermatol 2013; 31: 400-412.
Fig. 1-2. Pruritic cutaneous lesions on the chest
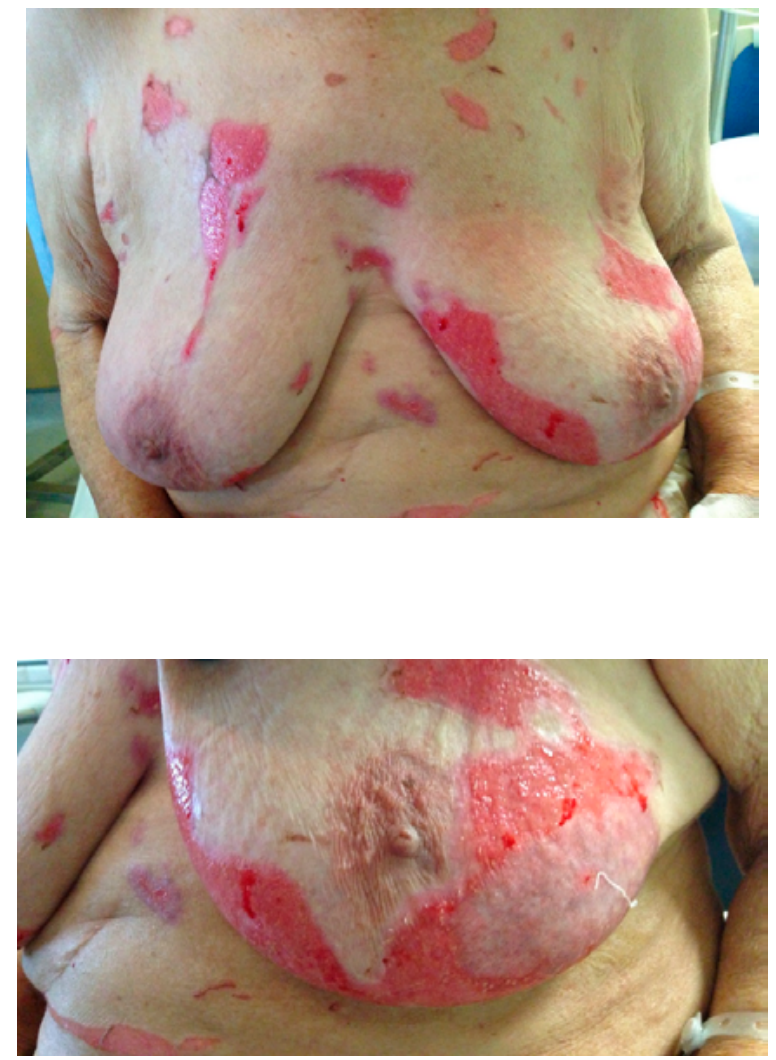

Diagnosis

\section{Cutaneous Manifestations of Gastric Neoplasm}

\section{Inês Zão, Carla Matias}

Centro Hospitalar do Baixo Vouga

Correspondencia: ineszao@gmail.com

Cómo citar este artículo: Zão I, Matias C

Pruritic cutaneous lesions on the chest. Galicia Clin 2019; 80 (3): 65

Recibido: 16/10/2018; Aceptado: 02/11/2018 // http://doi.org/10.22546/53/2020 